\title{
Immunoglobulin G Directed Against Toxins A and B of Clostridium difficile in the General Population and Patients with Antibiotic-Associated Diarrhea
}

\author{
Alfred E. Bacon III and Robert Fekety
}

Serum immunoglobulin $G$ (IgG) class antibodies directed against toxins $A$ and $B$ of Clostridium difficile were studied using an enzyme-linked immunosorbent assay and a serumneutralizing assay based on the MRC-5 tissue cytotoxicity assay. Of 185 individuals, 46 sera (24\%) in the general population demonstrated IgG antibody, 36 (19.4\%) against toxin $A$ and $15(8.1 \%)$ against toxin B. Antibody titer in the general

\section{INTRODUCTION}

The host immunologic response to the toxins of Clostridium difficile during and after episodes of $C$. difficile-associated diarrhea and colitis has not been well defined. In the hamster model of colitis, protection with vaccine prepared individually from toxins A or B attenuated disease. Protection was almost complete when vaccination was performed with a single toxoid derived from both A and B (Libby et al., 1982). Experience with human disease is limited. The ability of serum from patients with $C$. difficile disease to neutralize the cytotoxic effects of toxin in tissue culture assays has been demonstrated (Lishman et al., 1981; Nakamura et al., 1981). The rela-

From the Division of Infectious Diseases, Department of Medicine, University of Michigan Medical Center, Ann Arbor, Michigan, USA.

Address reprint requests to Dr. A.E. Bacon at his current address: Department of Medicine, Medical Center of Delaware, 4755 Ogletown-Stanton Road, PO Box 6001, Newark, DE 19718, USA. 1993

Received 9 July 1993; revised and accepted 6 December

Presented in part as an abstract at the Annual American Society for Microbiology Meeting in Atlanta, Georgia, 1987. (C) 1994 Elsevier Science Inc.

655 Avenue of the Americas, New York, NY 10010 $0732-8893 / 94 / \$ 7.00$ population did not correlate with serum-neutralizing activity. Antibody prevalence fell with age $(\mathrm{P}=0.58)$ over 50 years. Six of ten patients with acute primary episodes of $\mathrm{C}$. difficileassociated diarrhea demonstrated antibody in convalescentphase sera, predominantly directed against toxin $B$. Only two $(28 \%)$ of seven patients with a history of relapsing $C$. difficile disease had demonstrable antibody.

tionship of this serologic response to disease has not been described.

Serum immunoglobulin $M(\operatorname{IgM})$ and IgG antibodies directed against the toxins of $C$. difficile have been found with variable success in humans when enzyme-linked immunosorbent assay (ELISA) techniques are used (Aronsson and Granstrom, 1988; Aronsson et al., 1983; Viscidi et al., 1983). Antibodies to toxins $A$ and $B$ have been demonstrated in the sera of $>60 \%$ of the general hospitalized adult population (Viscidi et al., 1983). There has been less success demonstrating antibody in studying the nonhospitalized general population with similar techniques but different antigenic sources (Aronsson and Granstrom, 1988; Aronsson et al., 1983). No standardized antibody assay method has been recognized, and the antigenic preparations are of different source.

A retrospective evaluation of antibody response suggested that individual patients with diminished $\operatorname{IgG}$ antibody response to toxin $B$ were more likely to develop relapses of $C$. difficile (Aronsson et al., 1985). The host immune response to its toxins is yet to be well investigated. In this study, a modified indirect ELISA was used to evaluate the $\operatorname{IgG}$ host response to the toxins of $C$. difficile in patients with acute $C$. difficile diarrhea as well as in individuals 
with a history of relapsing disease. In addition, we used the same assay to evaluate the prevalence of $C$. difficile antibody in the general population and compared this with serum neutralizing activity.

Our assay uses a very well defined and described antigen preparation. In addition, a wide controlnegative population with strict definition allows for its increased specificity as well as sensitivity with appropriate cutoffs.

\section{MATERIALS AND METHODS}

\section{Sera}

Control-positive sera were identified by screening sera stored at $-70^{\circ} \mathrm{C}$ from patients with biopsyproven $C$. difficile colitis. Control-negative sera were obtained from individuals with the following criteria: (a) no history of hospitalization or employment in a hospital, (b) no antibiotic use for the preceding 2 years, (c) no history of diarrhea with antibiotic use, and (d) stool negative for C. difficile toxin and culture. General population sera were obtained from the American Red Cross Blood Bank (Detroit, MI, USA). The only information made available was the age of the blood donor. Sera from patients with primary episodes of $C$. difficile disease were defined as acute phase if obtained within 1 week of toxinpositive stool without prior history of disease and convalescent thereafter. There were 185 total sera from the general population, nine control-negative sera, ten patients with acute $C$. difficile disease, and seven patients with relapsing diarrhea studied.

\section{Toxins}

Purified toxin A and homogeneous toxin B of C. difficile VPI strain 10463 were provided and prepared as previously described (Lyerly et al., 1986). Essentially both proteins were purified by using ammonium sulfate precipitation with ion-exchange chromatography. Toxin A was further purified with precipitation at $\mathrm{pH} 5.6$ while an immunoabsorption chromatography was used to purify toxin B (Lyerly et al., 1986). All concentrations were standardized with a Biorad protein assay using a $\gamma$-globulin standard (Biorad).

\section{ELISA}

For the indirect ELISA, 96-well polystyrene plates (Dynatech, Alexandria, VA, USA) were used. Individual wells were coated with $100 \mu \mathrm{l}$ of solution of toxin A or B in phosphate-buffered saline (PBS, pH $=7.4$ ) at concentrations of $0.6 \mu \mathrm{g} / \mathrm{ml}$ (toxin A) and $1.0 \mu \mathrm{g} / \mathrm{ml}$ (toxin B). Optimal concentrations were determined by using a modified checkerboard technique. Coating was performed at room temperature, incubating for $16 \mathrm{~h}$. Plates were then washed five times with PBS with $0.05 \%$ Tween solution, stored dry at $4^{\circ} \mathrm{C}$, or used immediately. A total of $100 \mu$ l of sera diluted $1 / 200$ in PBS with $0.05 \%$ Tween and $0.5 \%$ Gelatin was added to the wells and incubated for $1 \mathrm{~h}$ at room temperature. Plates were again washed five times. A $100-\mu l$ solution of alkalinephosphatase-conjugated goat-anti-human IgG (Sigma, St. Louis, MO, USA) at a concentration of $0.22 \mu \mathrm{g} / \mathrm{ml}$ was then applied and incubated at room temperature for $1 \mathrm{~h}$. Plates were again washed five times and then developed with $100 \mu l$ of $p$-nitrophenyl phosphate substrate (Sigma) at a concentration of $5 \mathrm{mg} / \mathrm{ml}$ for $60 \mathrm{~min}$ with the resulting absorbance $\mathrm{Au})$ at a wavelength of $405 \mathrm{~nm}$ being determined on a Titertek Multiscan (Flow Laboratories, Costa Mesa, CA, USA).

All sera were run in duplicate and in an uncoated well to serve as control. The Au was determined by calculating the mean of the Au value in the antigencoated wells minus the Au value of the uncoated wells. On each plate, nine control-negative sera were run and one control positive. Plates were discarded if the background activity in the uncoated wells was $>0.150 \mathrm{Au}$ or if the control-positive serum was $<1.5 \mathrm{Au}$ (IgG toxin B antibody assay) or $<0.3$ $\mathrm{Au}$ (IgG toxin A antibody assay). A positive cutoff value for antibody $(\mathrm{Ab})$ titer was defined as the mean plus 3 standard deviations of the nine controlnegative sera $\mathrm{Au}$ from the same plate. This was designed to optimize specificity and sensitivity.

TABLE 1 ELISA Immunoglobulin G Antibody $(A b)$ versus Toxins $A$ and $B$ in the General Population

\begin{tabular}{lccccc}
\hline Age & No. & A Ab (\%) & B Ab (\%) & A + B Ab & Total (\%) \\
\hline $17-30$ & 58 & $14(24.1)$ & $2(3.4)$ & - & $16(27.5)$ \\
$31-40$ & 48 & $7(14.5)$ & $3(6.2)$ & 3 & $13(27.0)$ \\
$41-50$ & 37 & $8(21.6)$ & $1(2.2)$ & 1 & $10(27.0)$ \\
$51-65$ & 42 & $2(4.8)$ & $4(9.5)$ & 1 & $7(16.6)^{a}$ \\
Total & 185 & $31(16.7)$ & $10(5.4)$ & $5(2.7)$ & $46(24.8)$ \\
\hline
\end{tabular}

${ }^{a} P=0.58$. 


\section{Neutralizing Assay}

The MRC-5 tissue cytotoxicity assay was used to determine serum-neutralizing capacity for both toxin $\mathrm{A}$ and toxin $\mathrm{B}$. The minimum tissue cytotoxic dose (TCD by weight) in $50 \mu \mathrm{l}$ of solution (PBS) required to destroy $100 \%$ of cells in the tissue culture wells was defined as the $\mathrm{TCD}_{100}$. Mixed and incubated at room temperature for $1 / 2 \mathrm{~h}$ were $50 \mu \mathrm{l}$ of sera and $50 \mu \mathrm{l}$ of PBS with $4 \mathrm{TCD}_{100}$ equivalents. Then, $50 \mu \mathrm{l}$ (therefore containing $2 \mathrm{TCD}_{100}$ ) was then plated onto the MRC- 5 tissue culture microtiter wells. Serial dilutions of serum $1 / 5,1 / 10$, and 1/50 were performed in PBS ( $\mathrm{pH} 7.2$ ). The maximum dilution capable of inhibiting cytotoxicity was then recorded.

\section{Statistical Analysis}

Neutralizing activity and serum antibody comparison with age was made by univariant analysis. Chisquare was applied to all of the comparable data.

\section{RESULTS}

\section{General Population Sera}

Serum IgG antibody directed at the toxins of $C$. difficile was demonstrated in 46 of the 185 sera screened by ELISA (Table 1): $31(16.7 \%)$ had antibody versus toxin A only, $10(5.4 \%)$ toxin B only, and $5(2.7 \%)$ both toxins. When separated by age, the prevalence of $C$. difficile toxin antibody in those under 50 years of age was $\sim 27 \%$. Over the age of 50 and up to 65 years of age, the prevalence of antibody dropped to $16.6 \%(P=0.58)$.

A total of 111 sera were studied for toxin-A- or B-neutralizing capacity: 18 (16.2\%) neutralized toxin A, $24(21.6 \%)$ neutralized $B$, and $8(7.2 \%)$ neutralized both toxins. There was no correlation between ELISA-reactive sera and neutralizing capacity in the 111 sera run in both assays. Only five of 25 sera toxin $A$ antibody ELISA positive neutralized toxin $A$ in tissue culture. Of eight toxin B IgG antibodypositive sera, six did have neutralizing capacity. As Figures 1 and 2 show, there is no correlation with titer of ELISA antibody and neutralizing titer.

\section{Patient Sera}

Ten patients with acute, primary $C$. difficileassociated diarrhea were evaluated: eight with paired sera and two with convalescent phase only (Table 2). Six (60\%) demonstrated strong antibody titers to toxin B in convalescent sera. Only two (20\%) had toxin A antibody after disease. Of the four patients who failed to mount antibody to either toxin, two were on steroid therapy and one had received chemotherapy. No patient developed antibody to toxin A alone.

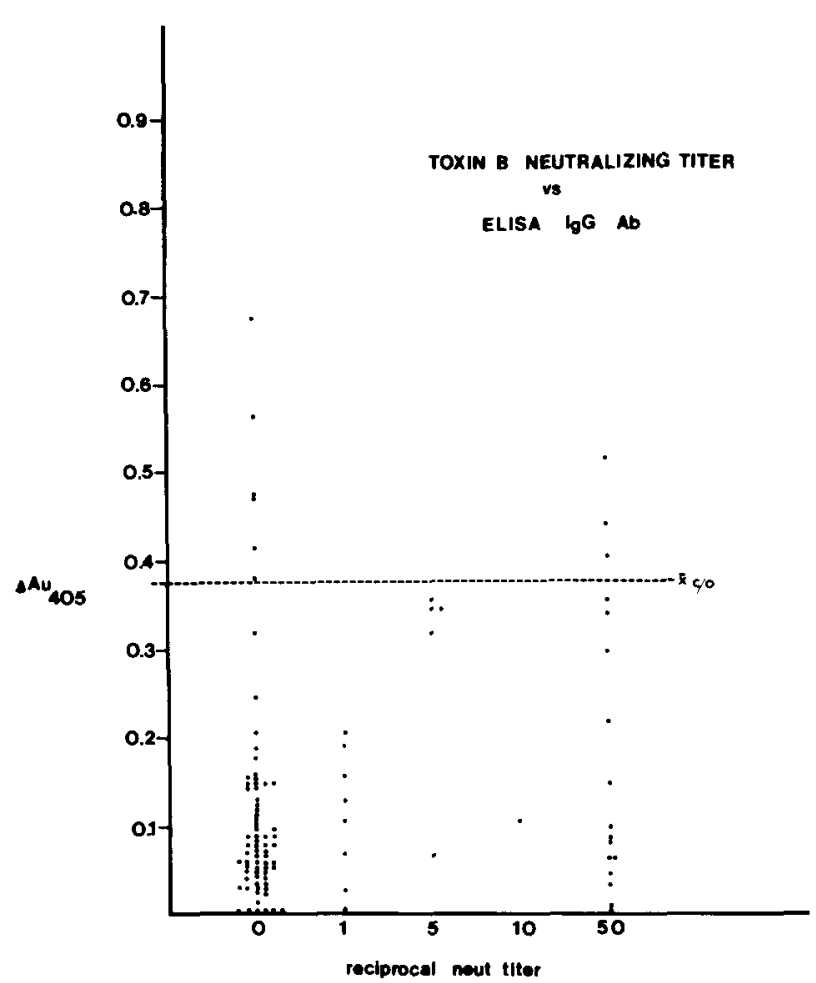

FIGURE 1 Toxin A antibody ( $\mathrm{Ab}$ ) by ELISA immunoglobulin $\mathrm{G}$ (IgG) compared with neutralizing titer in MRC -5 cytotoxicity assay.

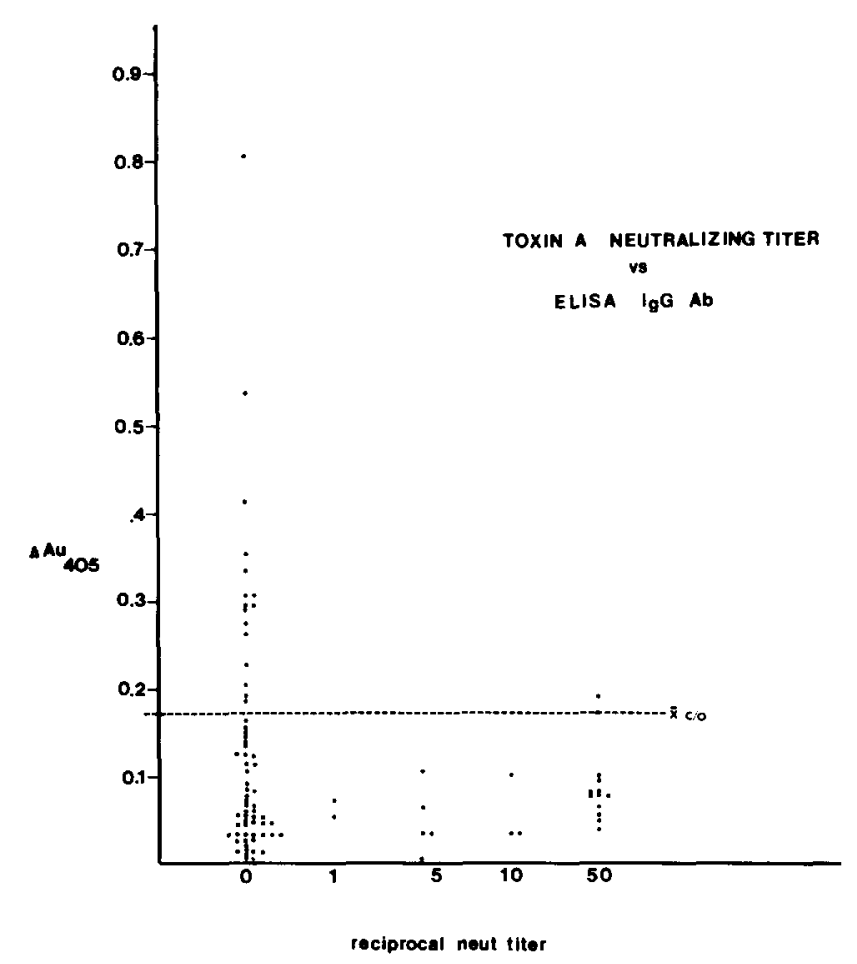

FIGURE 2 Toxin B antibody ( $\mathrm{Ab}$ ) by ELISA immunoglobulin $\mathrm{G}$ (IgG) compared with neutralizing titer in MRC-5 cytotoxicity assay. 
TABLE 2 ELISA Immunoglobulin G Antibody ( $\mathrm{Ab}$ ) versus Toxins $\mathrm{A}$ and $\mathrm{B}$ in Patients with Clostridium difficile Disease ${ }^{a}$

\begin{tabular}{|c|c|c|c|c|c|}
\hline \multirow[b]{2}{*}{ Patient } & \multirow[b]{2}{*}{ History } & \multicolumn{2}{|c|}{ Toxin $\mathrm{A} \mathrm{Ab}^{a}$} & \multicolumn{2}{|c|}{ Toxin $\mathrm{B} \mathrm{Ab}^{a}$} \\
\hline & & Acute $^{b}$ & Conv $^{b}$ & Acute $^{b}$ & Conv $^{b}$ \\
\hline 1 & Pyelonephritis & - & 0.035 & - & $0.668(+)$ \\
\hline 2 & Pneumonia & 0.028 & $0.403(+)$ & 0.0 & $0.853(+)$ \\
\hline 3 & Pneumonia & 0.008 & 0.000 & 0.194 & $0.339(+)$ \\
\hline 4 & Vascular disease & - & 0.0071 & - & $0.807(+)$ \\
\hline 5 & Osteomyelitis & 0.010 & 0.052 & 0.195 & $1.750(+)$ \\
\hline 6 & - & 0 & $0.150(+)$ & 0.008 & $0.204(+)$ \\
\hline 7 & Ulcerative colitis & 0.010 & 0.016 & 0.050 & 0 \\
\hline 8 & Sepsis & 0.057 & 0.000 & 0.026 & 0.058 \\
\hline 9 & NHL and CTX & 0.057 & 0.037 & 0.126 & 0.090 \\
\hline 10 & $\mathrm{COPD}^{d}$ & 0 & 0.045 & 0.004 & 0.021 \\
\hline
\end{tabular}

${ }^{a}$ ELISA antibody in absorbance units (Au).

${ }^{b}$ Acute-phase sera $<1$ week after toxin-positive stool, convalescent-phase sera $>1$ week after toxin positive stool, and $(+)$ denotes titer over "cutoff" ratio = "positive" titer.

"Non-Hodgkin lymphoma and chemotherapy.

${ }^{d}$ Chronic obstructive pulmonary disease.

In addition, seven patients with a history consistent with relapsing $C$. difficile disease were studied with random serum titers obtained as close to relapse as possible. These were sera referred to the University of Michigan from other sites after history was obtained and made available to us in writing. Only two $(28 \%)$ of the seven had demonstrable antibody despite multiple episodes and then to toxin B (Table 3).

\section{DISCUSSION}

The ability of the host to mount a systemic immune response to the toxins of $C$. difficile has been previously recognized (Aronsson and Granstrom, 1988; Aronsson et al., 1983 and 1985; Lishman et al., 1981; Viscidi et al., 1983). Early studies used serumneutralizing capacity (Lishman et al., 1981; Nakamura et al., 1981) while later investigators focused on ELISA technology (Aronsson and Granstrom, 1988; Aronsson et al., 1983 and 1985; Viscidi et al., 1983). Variability in assay conditions, particularly antigenic sources and "control" populations, makes it difficult to compare data directly. The results of our study do agree with previously published data in the low prevalence of antibody as measured by ELISA in the general population (Aronsson et al., 1983). Of interest is the finding of lower antibody prevalence in those individuals over the age of 50 . This is the age group most often noted to be at risk for the disease. Of individual sera of general population origin, $27 \%$ carry positive antibody to C. difficile toxins, predominantly toxin A. Others have noted a lack of correlation between neutralizing titer and ELISA IgG antibody except at high ELISA titers, where they do correspond (Aronsson et al., 1983; Viscidi et al., 1983). Individuals with high neutralizing titer in our study did not have positive ELISA

TABLE 3 ELISA Immunoglobulin G (IgG) Antibody (Ab) in Patients with a History of Relapsing Clostridium difficile Disease

\begin{tabular}{cllll}
\hline Patient & \multicolumn{1}{c}{ History } & Sera Date & $\operatorname{IgG~A~Ab} b^{a}$ & $\operatorname{IgG~B~Ab} b^{a}$ \\
\hline 1 & AML and CTX & At relapse & 0.017 & 0.059 \\
2 & Six relapses & 6 Mo post & 0.000 & 0.117 \\
3 & Mult relapse & 3 Days post & 0.000 & 0.007 \\
4 & Mult relapse & 2 Mo post & 0.016 & 0.023 \\
5 & Mult relapse & Prerelapse & 0.010 & 0.023 \\
& & Postrelapse & 0.016 & $1.673(+)$ \\
6 & Mult relapse & At relapse & 0.003 & 0.000 \\
7 & Mult relapse & 1 Mo post & $0.263(+)$ & $1.728(+)$ \\
\hline
\end{tabular}

${ }^{a}$ ELISA antibody expressed as absorbance units (Au).

${ }^{b}$ Chemotherapy. 
antibody titers. The possibility exists that antibody avidity diminishes with time, or that the assays are identifying antibody directed at different portions of the toxins and therefore the steric constraints of ELISA technique may limit our ability to search for the appropriate antibody. This discrepancy warrants further study.

Of our patients with documented acute primary C. difficile-associated disease, $60 \%$ were found to have significant antibody titers by ELISA. This degree of seroresponse has been described by others (Aronsson et al., 1985). Of the patients without seroconversion, three received immunosuppressive therapy prior to the development of diarrhea. Individuals receiving steroids, chemotherapy, or with underlying diseases leading to immunosuppression represent the population most at risk for disease with $C$. difficile. The relationship between the disease state and the host response in this group may be pertinent to understanding the processes leading to relapse or prolonged illness.

In the seven patients studied with a history of relapsing $C$. difficile colitis, a much lower rate of seropositivity ( $28 \%$ ) was found than in those patients with acute disease $(60 \%)$. This seroprevalence approaches that found in the general population; however, the two patients who were seropositive had antibody directed against toxin $B$ in distinction to the general population data, where toxin $B$ antibody is unusual $(5.4 \%)$. It has been suggested that those patients who do not develop antibody specifically directed at toxin $B$ are at risk for relapse (Aronsson et al., 1985). It appears that toxin B is more immunogenic during natural disease with $C$. difficile, as all our seropositive patients with primary $C$. difficile mounted extremely high titers to toxin $B$ and less often converted to toxin A seropositivity. Toxin A, considered less cytotoxic by weight, does not appear to induce a significant serologic response. It should be noted that even our control-positive sera

\section{REFERENCES}

Aronsson B, Granstrom M (1988) Immunological response to Clostridium difficile infection. In Clostridium difficile: Its Role in Intestinal Disease. Eds, RR Rolfe and SM Finegold. San Diego: Academic, pp 100-111.

Aronsson B, Granstom M, Mollby R, Nord CE (1983) Enzyme-linked immunosorbent assay (ELISA) for antibody to Clostridium difficile toxins in patients with pseudomembranous colitis and antibiotic associated diarrhea. J Immunol Methods 60:341-350.

Aronsson B, Granstrom M, Mollby R, Nord CE (1985) Serum antibody response to Clostridium difficile toxins in patients with Clostridium difficile diarrhea. Infection 13:3-7.

Libby JM, Jortner BS, Wilkins TD (1982) Effects of the two had a very low titer by ELISA $(0.3 \mathrm{Au})$. This individual had well-documented neutralizing capacity.

The ability of immunologic competence against the toxins to mediate the disease state has been documented in the hamster model of disease (Libby et al., 1982). Growing evidence does support the possibility that individuals that relapse with the disease may also demonstrate a lowered immune response. The issues surrounding relapsing $C$. difficile disease are complex, and the true role of the host response is yet to be fully defined. Of particular interest will be the length of time after disease where antibody titers can be assessed, and the association of those titers with relapse as well as severity of primary disease or even the association of antibody response to treatment options.

Our ELISA assay is comparable to those previously described (Aronsson, et al., 1983 and 1985; Viscici et al., 1983). The assay described in this report, however, has an improved antigen source and well-defined control population. The toxin preparations represent optimal purity. The use of a large control-negative population in our study and standardized positive controls improves the specificity particularly with the use of nine negative controls run on each plate with a cutoff defined as the mean plus 3 standard deviations. Our lack of correlation between neutralizing capacity and ELISA titer in the general population will need further study and suggests the potential need for additional immunologic techniques, where the binding of the toxin to plates may not affect the nature of the assay system.

This work was supported by grant 5R01 AM-21076-06 from the National Institute of Arthritis, Diabetes, and Digestive and Kidney Diseases. The authors acknowledge the help of Dr. David Lyerly and Dr. Tracy Wilkins, who supplied toxins $A$ and $B$ for the study. toxins of Clostridium difficile in antibiotic-associated cecitis in hamsters. Infect Immun 36:822-829.

Lishman A, Al-Jumaili I, Record C (1981) Antitoxin production in antibiotic-associated colitis. I Clin Pathol 34: 414-415.

Lyerly DM, Roberts MD, Phelps CJ, Wilkins TD (1986) Purification and characterization of toxins $A$ and $B$ of Clostridium difficile. FEMS Microbiol Lett 33:31-35.

Nakamura S, Mikawa M, Nakashio S, et al. (1981) Isolation of Clostridium difficile from the feces and the antibody in sera of young and elderly adults. Microbiol Immunol 25:345-351.

Viscidi R, Laughon BE, Yolken R, et al. (1983) Serum antibody response to toxins $A$ and $B$ of Clostridium difficile. I Infect Dis 148:93-100. 